\title{
EXPLOTACIÓN ECONÓMICA DE LOS MUSULMANES DEL VALLE DEL EBRO: PARIAS Y ALMOTEXENAS ABONADAS A LOS REINOS DE ARAGÓN Y NAVARRA DURANTE EL SIGLO XI
}

ECONOMIC USE OF MUSLIMS IN THE EBRE VALLEY: PARIAS AND ALMOTEXENAS PAID TO THE KINGDOMS OF ARAGON AND NAVARRE DURING THE $11^{\text {TH }}$ CENTURY

\author{
Adrián Elías Negro CoRTÉs \\ Universidad de Extremadura, Cáceres
}

\begin{abstract}
Resumen: Este trabajo busca descubrir los pagos que recibieron los reinos de Aragón y Navarra de los musulmanes durante el siglo XI. La principal institución que se analizará son las parias, pagos realizados desde los poderes políticos musulmanes hacia los cristianos para asegurarse la paz, pero también estudiaremos la almotexena, un tipo de impuesto que se aplicaba sobre los habitantes musulmanes de aldeas fronterizas. A continuación iremos desgranando las referencias documentales a almotexenas en Aragón y a parias en Aragón y Navarra para cerrar nuestro estudio con una cronología aproximada de los pagos.
\end{abstract}

Palabras clave: parias, frontera, Aragón, Navarra, siglo XI.
Abstract: This text aims to unveil the payments received by the kingdoms of Aragon and Navarra from Muslims during the $11^{\text {th }}$ Century. The main institution we will analyse are the parias, which were payments made by the Muslim taifa kingdoms to Christian kingdoms to assure peace. Also we will study the almotexena, which is a taxation that was imposed on the Muslim inhabitants of little villages in the frontier between Aragon and Zaragoza. Afterwards we will explain all the references in archive documentation to almotexenas in Aragon and parias in Aragon and Navarra to end with an approximate chronology of the payments made.

Key words: parias, frontier, Aragón, Navarra, $11^{\text {th }}$ Century. 


\section{Introducción}

El objetivo de este trabajo es realizar una cronología de los pagos que los musulmanes del valle del Ebro realizaron a los reinos de Aragón y Navarra durante el siglo XI. La principal institución que vamos a analizar son las parias, que son pagos que una entidad política musulmana, bajo coacción militar, abonaba a una entidad política cristiana, en moneda, a cambio de un cese inmediato de los hostilidades o el mantenimiento de una situación de relativa paz. (Negro, 2013: 383).

Hemos incluido también en el estudio la almotexena, que era un tributo que abonaban las poblaciones musulmanas que vivían en zonas fronterizas bajo el dominio teórico de la taifa de Zaragoza, pero que en la práctica ésta ya no podía defender, por lo que estas localidades se encontraban en una especie de tierra de nadie, quedando a merced de los ataques aragoneses. La analizaremos porque pensamos que es un concepto que es próximo al de paria, aunque no idéntico. Por otro lado, algunos autores como Laliena (1996: 121), igualan almotexenas y parias.

Si bien el tema de las parias ya ha sido parcialmente analizado con anterioridad para los casos aragonés (Lacarra, 1981a) y navarro (Rodríguez Latorre, 1995: 249), hasta el momento no se ha realizado una relación cronológica completa de todos los pagos y de las referencias documentales y cronísticas a estos en Aragón y Navarra, ni en el conjunto de la Península Ibérica. Tampoco se había estudiado en profundidad la institución de la almotexena, que aparece en la documentación aragonesa del siglo XI.

Los pagos de parias han sido estudiados con anterioridad para otros escenarios y cronologías. Un buen ejemplo es el ya clásico trabajo de Grassotti sobre Castilla-León (Grassotti, 1964) en el que asocia parias y botín en un estudio que abarca desde los primeros abonos en el siglo xi hasta el reinado de Alfonso XI. Bishko trató el tema también para Castilla (Bishko, 1980: 50-51) con el objetivo de descubrir de dónde salió el dinero para abonar el famoso censo a Cluny, que se inició bajo el reinado de Fernando I. En fecha más reciente García Fitz (García Fitz, 2002: 63) consideró estos pagos como una parte clave de la estrategia de debilitamiento y disolución establecida por Alfonso VI de cara a facilitar el avance de las tropas castellanas hacia el sur. También contamos con un recién publicado estado de la cuestión realizado por Negro en 2017. 
La zona catalana, donde encontramos las primeras referencias documentales a las parias, también ha gozado de atención por parte de los estudiosos del fenómeno. El primer estudio de las parias, basado principalmente en documentación de archivo, fue realizado por Balari en 1899 (Balari, 1964: 333336) dentro de su obra Orígenes históricos de Catalunya.

Otros autores han analizado tangencialmente las parias catalanas, por ejemplo Balañá (1993: 110) recoge un resumen de los pagos a mediados del siglo xI; Salrach (1987: 323) considera las parias como un elemento esencial en la centralización del poder en manos del conde de Barcelona; y Bonnassie (1975: 867) ofrece una lista de los reinos taifas que podían estar pagando parias a los condados catalanes. Kosto (2001: 13) considera que las entregas monetarias estarían detrás del despegue económico de la zona catalana durante la segunda mitad del siglo XI.

También Negro analizó la realidad de las parias para el caso del reino nazarí de Granada entre 1246 y 1464 (Negro, 2013); este autor puso de manifiesto que el reino granadino abonó parias durante aproximadamente la mitad de su trayectoria política, aunque los pagos tuvieron una importancia mucho menor que en el caso de las parias del siglo XI. Resulta difícil hacer un recorrido por todo lo que se ha escrito sobre las parias, ya que cualquier autor que ha tratado el siglo XI tanto para el lado musulmán como para el lado cristiano, bien en manuales generales o en obras sobre cualquier aspecto más concreto del período, aborda el tema. No obstante, los trabajos citados se encuentran entre los más destacados.

Las parias tuvieron su origen en la frontera bizantino-musulmana durante el siglo VII, extendiéndose en ese mismo escenario hasta el momento de las Cruzadas, aunque en ningún momento aparecerá el vocablo 'paria' en la documentación procedente de esta frontera. Un ejemplo de estos pagos es descrito por Teófanes, cronista bizantino del siglo VIII, en el siguiente pasaje: «In this year peace was concluded between Romans and Arabsil after Mauias had sent an embassy, because of the rebellion (la guerra civil contra 'Ali) offering that the Arabs should pay the Romans a daily tribute of 1,000 solidi, one horse, and one slave». (Teófanes el Confesor, 1997: 464).

Los primeros pagos de parias que encontramos en la Península Ibérica datan de la década de 1040. Son entregas monetarias efectuadas desde las taifas de Zaragoza, Lleida o Tortosa al condado de Barcelona. Entre 1050 y 1090 los reinos cristianos, sobre todo la Castilla de Fernando I, el más poderoso, some- 
terán a los diferentes reinos taifa a pagos de parias. Por ejemplo, nos consta que Castilla cobró parias de Sevilla, Toledo, Badajoz, Granada y Zaragoza. La taifa hudí era la que tenía una situación geopolítica más complicada: encajonada entre Aragón, Navarra, Castilla y los condados catalanes, sus parias fueron siendo entregadas unas veces a unos reinos y otras veces a otros.

El régimen de parias del siglo xi llegó a su fin con la entrada de los almorávides y su conquista de las primeras taifas, pero resurge de nuevo en el período de las segundas taifas, cuando Ibn Mardanish (Lacarra, 1952: 522) y Sayf al-Dawla, el Zafadola de las crónicas cristianas (Pérez, 1997: 72), abonan cuantiosos pagos a Castilla y Aragón. Finalmente desde 1246 el reino nazarí de Granada pagará parias a Castilla hasta que en 1492 la desaparición de este reino, última entidad política musulmana en la Península Ibérica, acabe definitivamente con esta fuente de beneficios.

Aragón y Navarra obtuvieron dinero de la taifa de Zaragoza bien en forma de parias, bien a través de almotexenas de los musulmanes que vivían en zonas fronterizas (solo en el caso aragonés). Ello fue debido a que la hudí era la taifa más cercana y su capacidad militar impedía a los reinos cristianos acceder a otras taifas musulmanas más alejadas. Algo que sí conseguió la Castilla de Alfonso VI, que llegó a someter a parias a taifas tan lejanas a su territorio como Granada (Abd Allah, 1981: 228).

\section{Parias y almotexenas abonadas al reino de Aragón}

El testamento de Sancho III el Mayor de 1035 será el que determine la geografía política de los reinos cristianos durante la plena y la baja Edad Media peninsular. Este rey navarro dividió sus reinos entre sus cinco hijos. Al primogénito, García, le dio el territorio de la dinastía, Navarra. A otro hijo, Fernando, le concedió el reino de Castilla. El reino de Aragón recayó en otro de sus retoños, Ramiro I, que reinó hasta 1063, cuando perdió la vida en la campaña contra Graus. A los dos hijos menores les otorgó los condados de Sobrarbe y Ribagorza, pequeñas unidades territoriales que pronto quedarían subsumidas en el reino de Aragón.

Aragón contaba con una desventaja estratégica respecto de Castilla. Mientras que la frontera sur de Castilla - el mal llamado desierto del Duero- apenas fue colonizada por los musulmanes y, por tanto, el reino castellano gozaba de más espacio tanto para expandirse militarmente como para crecer económi- 
camente mediante roturaciones y presuras, el valle del Ebro, que se situaba en la frontera sur de Aragón, había sido ampliamente colonizado por los musulmanes y éstos habían construido fortalezas para defender esta frontera, como por ejemplo Barbastro o Graus.

Por tanto, el territorio del reino aragonés, pequeño y muy montañoso, unido a la potencia militar zaragozana, dificultó en primera instancia expediciones de conquista hacia el sur. A título ilustrativo, cabe recordar que entre la capital del reino de León, León, y la siguiente ciudad musulmana de importancia, Toledo, había cerca de $400 \mathrm{~km}$ de zona poco poblada. Por el contrario, entre Jaca, sede de la corte aragonesa, y Huesca había $70 \mathrm{~km}$ llenos de fortalezas defensivas.

Además, las primeras ofensivas aragonesas se toparon con feroz resistencia a cargo de los zaragozanos, sufriendo derrotas como la de Graus en 1063 o la reconquista de Barbastro a cargo de los hudíes en 1065. La primera victoria de consideración que los cristianos obtuvieron en la zona, la toma de Barbastro en 1064, no fue obtenida por los ejércitos aragoneses, sino por una amplia coalición de cruzados franceses y normandos que además solo pudieron retener la ciudad nueve meses.

Todo ello dificultó y retrasó el avance aragonés hacia el sur. Mientras Alfonso VI tomaba Toledo en 1085, hasta 1096 no conquistó Pedro I Huesca y hasta 1118 no pudo hacerse Alfonso I con Zaragoza (a solo $143 \mathrm{~km}$ de Jaca).

\subsection{La almotexena o almutegena}

El primer testimonio documental que tenemos de pagos de musulmanes a Aragón es un diploma de Ramiro I de 1049 en el que el monarca hace una donación al monasterio de San Victorián. Aparte de otra serie de bienes, se dona a este monasterio «de quantas almotexenas ad nostram partem prehendiderimus de Maritero usque in Esera et de serra de Arb in intro» (Viruete, 2013: 396). El editor de este diploma afirma que es una paria, sin embargo no entraría dentro de la definición que nosotros hemos aportado del fenómeno. Tampoco aparece el vocablo paria en ningún momento.

En 1049, la zona a las que hace referencia el diploma - el valle del río Ésera y la sierra de Arbe - era una zona fronteriza con la taifa de Zaragoza con todas las implicaciones que eso conlleva. De hecho, la zona está dentro del área de influencia de Barbastro, de la que dista unos $30 \mathrm{~km}$. Había formado parte del gran reino navarro de Sancho III, quien edificó en 1023 un castillo 
en Abizanda, en el centro de la sierra de Arbe. Pero no podemos concluir con seguridad si Aragón dominaba políticamente la zona en este momento, probablemente se tratara de una zona fronteriza sin un dominador claro.

Lo que se dona al monasterio es un tributo que pagan los musulmanes, al que se denomina almotexena. Esta institución fue definida por Tomás Faci como «una variante fonética o mala lectura de 'almotacena', esto es, el derecho que cobraban los almotacenes o vigilantes de los mercados» (Tomás, 2013: 378) y, según él, no aparece mucha documentación en la que haya referencias a esa almotexena. Para Lapesa, el vocablo 'almotexena' y sus variantes 'almotexania', 'almotogena', 'almudegana', 'almudegena' y 'almutegena' significan impuesto o contribución y se trataría de una palabra de origen árabe, sin concretar nada más (Lapesa et alii, 2003: 39-40). Para Corriente, el vocablo 'almotexenas' se referiría a los poblados mudéjares y, por metonimia, la recaudación de tributos que generaban (Corriente, 2003: 398).

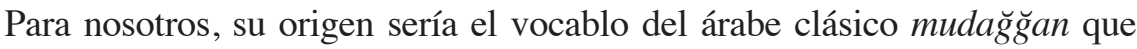
deriva de la raíz $d-\breve{g}-n$ que también da origen a la palabra mudéjar, por ejemplo,

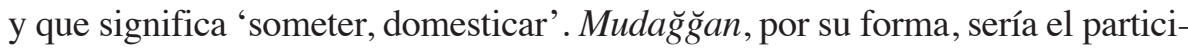
pio pasivo de un verbo en forma II y significaría 'el sometido, el que se somete'.

Por lo tanto pensamos, basándonos en su origen etimológico, que la almotexena sería un tributo especial impuesto a los musulmanes que vivían en esa zona fronteriza que carecía de un dominador claro, siendo zona sin dueño. El sometimiento a Aragón sería económico, pero no político. Dado que no hemos encontrado referencias a almotexenas a partir del siglo xir y la tributación mudéjar, estudiada por Ledesma (1996), no recoge este término, pensamos que al caer estas localidades bajo el dominio efectivo del reino de Aragón la almotexena quizás fuera sustituida por otra figura tributaria.

Las referencias a recaudaciones de 'almotexenas' en la documentación, siempre en Aragón, se refieren a territorios que no forman parte del reino aragonés y que están en estas zonas fronterizas cuyo dominador no está claro.

Otro ejemplo de almotexena lo encontramos en un documento fechado en 1035 , pero que es falso. En este documento aparece una referencia a almotexenas obtenidas de Abbarola (actual Alberuela de Laliena, Huesca) y de Gradus (Graus) «Et dono [i]psa decima de ipsa almutegena que ad mea parte est de Gradus usque ad Abbarola de paie et de uino de auro de argento de trappoz de omnia que inde accipio uel de inceps accipiturus sunt» que se donan al monasterio de San Victorián (Viruete, 2013: 286) pero Aragón no tomó Graus 
de manera definitiva hasta 1083, bajo el reinado de Sancho Ramírez (Ubieto, 1981: 84).

El documento, según Martín Duque, es una falsificación realizada en el scriptorum del monasterio de San Victorián a partir de la segunda mitad del siglo XII (Viruete, 2013: 132), por eso se da la fortaleza de Graus como ya tomada. Además contamos una sentencia otorgada por Pedro I en 1095 resolviendo una disputa entre San Victorián y Santa María de Alquézar sobre este tema: «Contendebant super illam ecclesiam de Nabal et super decimam de almudegena quod dedit rex Ranimirus avus meus et pater meus Sancius ad Sanctum Victorianum, de Albarola usque in Gradus de tota almudegena, totam decimam ab integro [...] et habeat sancte Marie Alquezari similiter et tota alia almudegena de pane et vino» - (Ubieto, 1951: 234) - , que probablemente dio la idea al falsificador del otro documento.

Como vemos en ambos documentos, la almotexena se puede pagar en especie - pane et vino - , se podría pagar en metal precioso - auro et argento - o una combinación de ambas, como da a entender la donación supuestamente a cargo de Ramiro I. Dado que este documento es falso, albergamos ciertas reservas sobre el uso de metal precioso en el pago de estas contribuciones. Pensamos más bien que, dada la escasa monetización del reino aragonés en el siglo XI (Utrilla, 2006: 543), estos tributos se pagarían regularmente en especie, sin perjuicio de que algún mercader mudéjar pudiera conseguir moneda árabe de oro o plata acuñada en Zaragoza mediante el comercio y pudiera optar por pagar en moneda, dado que la almotexena se cobra en zonas fronterizas.

El resto de veces que este vocablo aparece en la documentación lo hace en contextos más generales. En el Libro de la Cadena del obispado de Jaca encontramos otra referencia en un documento fechado en 1076 en el que se determinan los límites y privilegios del obispado de Jaca: «Concedo quoque et corroboro eisdem canonicis decimam telonei regalis de Iacca atque decimam tributi regalis de Yspania et almutegenam de villis Hispaniae» (Sangorrín, 1921: 66). No se hace referencia concreta a las villas, aunque la zona de Hispania hace referencia a la zona sur del obispado de Jaca, según Sangorrín. Es muy probable que así sea, pues las localidades que nos han aparecido explícitamente en las fuentes como pagadoras de almotexena pertenecen a ese ámbito geográfico. En general, el vocablo Hispania en la documentación altomedieval se refiere a zonas dominadas por los musulmanes, una de las razones por la que concluimos que las aldeas pagadoras de almotexena aún no formarían parte integrante del reino de Aragón. 
En 1083 Sancho Ramírez dona al monasterio de San Juan de la Peña la cuarta parte de las almotexenas de Sangarrés, Vicién, Pueyo de Vicién, Tabernas, Buñales, Torres de Violada, Torres de Almuniente, Barbués, Callén, Almudévar, Formígena y Pitellas, poblaciones que ya se encuentran al sur de Huesca, que no será conquistada hasta 1096 (Salarrurana, 1909: 63; Canellas, 1993: 71). En 1100 su hijo Pedro confirmará esta donación (Ubieto, 1951: 323). Tanto Huesca como su zona sur, donde se sitúan las localidades que abonan almotexena, serían conquistadas por Pedro I, por lo que en 1083 aún no forman parte del reino de Aragón, sino que están en esa zona fronteriza sin dominador claro a la que hemos aludido anteriormente (Ubieto, 1981: 118119). Estas doce poblaciones vuelven a ser mencionadas como pagadoras de almotexena en 1101, en una carta de permuta entre Pedro I y el abad Sancho de San Juan de la Peña (Ubieto, 1951: 349).

En otro documento, fechado en 1095 y conservado en el Archivo de la Corona de Aragón aparece la donación de «tres uillas almotexanias de mauris», sin especificar de qué poblaciones se trata (Ubieto, 1951: 267). De ese mismo año es otro diploma otorgado por la condesa doña Sancha, hija de Ramiro I y hermana de Sancho Ramírez que dona al monasterio de San Pedro de Siresa «tres uillas almotexanias de mauris quas dedit mihi frater meus rex Sancius [...] nomina earum sunt Molinus, Askasas et Conilgena» (González Miranda, 1955: 199-200), aldeas situadas en el término municipal de la localidad de Monforte-Lascasas, a $8 \mathrm{~km}$ al sur de Huesca, donde se sitúa el aeropuerto oscense en la actualidad (Pastor Sánchez, 2005). Éstas le habían sido cedidas por su hermano. Es de destacar la referencia a «mauris» o moros como pagadores del impuesto en ambos documentos.

A veces los vocablos almotexena y paria aparecen en el mismo documento pero refiriéndose a realidades distintas. Por ejemplo, en un diploma de 1093 en el que Sancho Ramírez confirma una serie de donaciones realizadas por él y su hijo Pedro a la iglesia de Jesús Nazareno situada en el castillo de Montearagón, próximo a Huesca, se le concede a esta iglesia la décima parte de las almotexenas que se recibían del territorio que se encuentra entre los ríos Gállego y Alcanadre, cuya extensión es bastante grande.

Pero un poco más abajo aparece el vocablo parie: «Damus quoque decimam parie quam persoluunt iudei habitantes in uilla qui dicitur Lizarrarella». El vocablo 'paria' deriva del verbo latino pendo, «pagar». Por ello 'paria' en el siglo XI y anteriores también puede significar cualquier tipo de pago y no necesariamente el abonado por reinos musulmanes. 
En este caso, parie hace referencia a los tributos pagados por los judíos de la zona de Lizarrarella, no localizada completamente en la actualidad, pero que según Miranda (2008: 187) podría corresponder al barrio campesino de Lizarrara absorbido por Estella, la propia Estella o la población de Sangüesa. En cualquier caso, se trataría de una localidad perteneciente al reino de Navarra situada relativamente lejos de la frontera, por lo que no es una paria, simplemente el tributo que los judíos habían de abonar a la corona aragonesa.

Del examen de estas referencias podemos concluir que durante el siglo XI la almotexena fue un tributo que se cobraba a los musulmanes que vivían en poblaciones fronterizas entre la taifa de Zaragoza y Aragón, que se situaban en el lado zaragozano de la frontera pero que la taifa hudí ya no controlaba y por ello se encontraban en una especie de tierra de nadie. Los reyes aragoneses contaban con esos ingresos y disponían de ellos: donaban parte de ellos a instituciones eclesiásticas o los repartían entre su familia.

Son tributos con vocación de continuidad, pagados por musulmanes, pero a título individual. No es un estado taifa, ni siquiera una fortaleza independiente quien se hace cargo de pagar la almotexena, sino que son los propios habitantes musulmanes de una población que no tiene un dominador claro. Por todo ello, no creemos que esta institución sea una paria. Es una almotexena, una institución diferenciada.

La almotexena se trataría de una institución privativa de la zona aragonesa, puesto que solo aparece en la documentación de este reino entre 1049 y 1110 , fecha a partir de la cual no encontramos más referencias.

\subsection{Las parias}

En la documentación aragonesa también encontramos varias referencias a parias. La primera es del reinado de Ramiro I (1035-1063), de fecha indeterminada. Es un juramento de fidelidad de Ramón IV o V, conde de Pallars, al rey aragonés, que formaba parte del archivo condal de Barcelona. El conde de Pallars se compromete, entre otras cosas, a no interferir en los pagos de parias que recibe el rey aragonés.

$\mathrm{Al}$ igual que la fecha, no queda muy claro qué poderes musulmanes pagan, pues las parias que se cobran proceden ex partibus Hispaniae. Esta expresión aparece repetidamente en documentación catalana y probablemente se refiera a Zaragoza y Lleida. También se fijan condiciones en el caso de que las parias 
se incrementen, otra cláusula que veremos continuamente repetida a lo largo de la documentación, tanto catalana como aragonesa (Baigés et alii, 2010: 196-197). Por lo tanto, se espera que la paria se vaya incrementando con el tiempo.

En 1063 Ramiro I y su hijo y sucesor Sancho Ramírez dotan la diócesis de Jaca porque acababa de ser restaurada en un concilio provincial. Entre otras cosas, se le da a esta diócesis «ex ipsis tributis que recipimus in presenti uel recipere debemus aut in futuro Deo miserante recipiemus de Caesaraugusta necnon et Tutela de omnibus terciam partem ipsius decimationis supradicte ecclesie et episcopo concedimus et donamus.»

Se le concede un tercio de la décima parte de las parias - llamadas en este texto tributos - pagadas por Zaragoza y Tudela (Zurita, 1976: 70). Recordemos que Tudela no fue conquistada por Aragón hasta febrero de 1119. Formó parte del reino hudí hasta la caída de éste en manos de los almorávides. El hecho de que se cite en este documento en pie de igualdad con Zaragoza nos hace pensar que Tudela podía tener cierto grado de autogobierno en ese momento.

De 1069 data un pacto entre Al-Muqtadir, rey de Zaragoza y Sancho Ramírez de Aragón en el que se acuerda que el rey aragonés protegerá a la taifa hudí en contra de sus enemigos, probablemente Navarra y los condados catalanes. Hay cierta discusión sobre quién es el Sancho que menciona el texto. Lacarra (1981b: 84-86), el primer historiador contemporáneo que dio a conocer el tratado, afirmó que Al-Muqtadir estaba firmando el pacto con Sancho Garcés IV de Navarra; y otros historiadores, como Lapeña, coincidieron con esta propuesta (Lapeña, 2004: 166). Pero nosotros seguimos la opinión de Laliena, que afirma fundadamente que el Sancho al que se refiere el pacto es Sancho Ramírez de Aragón (Laliena, 2009: 203).

A cambio de la protección de Aragón, Al-Muqtadir tiene que entregar «mille numos de auro bono per singulos meses sicut in ligamento transacto confirmatum est, et det illi ex inde denantatos quinque millia numos de auro bono per quinque menses futuros, est primum mensis mense aprile era M.C.VII ${ }^{\mathrm{a}}$ et de supradictis quinque millia, habeat ex eis in ora istius ligationis duo millia quingentos numos auro bono, et ipsos alios duo millia quingentos qui remanent ut uadat pro eis suus fidelis de suos bonos barones ad Caesaraugustam et adducere faciet eos in exitu de isto mense primo maio» (Lacarra, 1981a: 9293). Es decir, tenía que pagar mil dinares todos los meses, como decía un pacto finalizado - ligamento transacto - , que nos da a entender que este pac- 
to que examinamos no es el primero ni el único que existió, sino que habría algún tratado de protección anterior que ligaba a ambos reyes.

Como es lógico, los reyes de Zaragoza y Aragón no podían reunirse cada mes para que Al-Muqtadir pagara sus parias, así que se arbitra el siguiente procedimiento: los cinco mil dinares que corresponderían a los pagos de los cinco siguientes meses se pagarán en dos plazos de 2.500 dinares, el primer plazo se haría inmediatamente efectivo tras la firma del pacto y el segundo se haría efectivo a finales del siguiente mes de mayo, cuando una embajada aragonesa de confianza vaya a visitar Zaragoza.

De este pacto deducimos que Zaragoza llevaba pagando la cantidad de 1.000 dinares mensuales durante un período de tiempo relativamente largo, que sin duda superaba el año. Pensamos que existirían más tratados anteriores a éste, pero desgraciadamente sólo se ha conservado otro posterior, de 1073 entre Al-Muqtadir y, esta vez sí, Sancho Garcés IV de Navarra, que se tratará en el apartado dedicado a Navarra.

En 1091 Sancho Ramírez, junto a su sucesor Pedro, concedió a la iglesia consagrada a San Pedro de la fortaleza de El Castellar una parte de las parias percibidas del reino hudí de Zaragoza: «damus ei de ueteri paria Caesarauguste ciuitatis quantum dari solet Pampilonensi ecclesie; de noua uero paria totam decimam» (Canellas, 1993:124-125; Moret, 1969: 173). La fortaleza, llamada Supercaesaraugusta en la documentación, se estaba construyendo en ese momento. Además también concedieron a esta iglesia la décima parte de los ingresos obtenidos en botines y algaras: «Damus etiam de portu et de salinis, de ortis et de molinis, de omni algaria et azaria que fecerint habitatoris iam dicti castri totam decimam, et regali parte similiter.» (Moret, 1969: 173)

Según este documento, con anterioridad a 1091 Aragón estuvo recibiendo parias de Zaragoza. Parte de esas parias se entregaron al obispado de Pamplona - que estaba bajo el gobierno aragonés desde 1076- y se pretendía obtener un nuevo abono de parias en un futuro inmediato.

Los restos de la fortaleza de El Castellar se encuentran en el término municipal de Torres de Berellén, que está a unos $30 \mathrm{~km}$ de Zaragoza, camino de Tudela. Se trata de un castillo que se edificó muy al sur: recordemos que Huesca no se conquistó hasta 1096 y cinco años antes se está construyendo una poderosa fortaleza $100 \mathrm{~km}$ al sur de esta ciudad.

La fortaleza de El Castellar se construyó con el propósito de presionar militarmente a la taifa de Zaragoza. De hecho el nombre que se le da a la forta- 
leza, «Supercaesaraugusta», es muy expresivo. Por eso el diploma vaticina que se va a recibir un nuevo envío de parias en un plazo breve de tiempo, de ahí la referencia a «nova paria» y su distinción de la «veteri paria». La «nova paria» que se pretendía conseguir es probablemente superior a la «veteri paria» que Zaragoza estaba pagando.

Si analizamos detenidamente esta concesión real, da la impresión de que Sancho Ramírez estaba siendo muy generoso. El rey aragonés pretendía que los habitantes de esta fortaleza estuviesen bien provistos y trataba de animar a posibles pobladores a habitarla. La distinción entre «nova paria» y «veteri paria» no es sino otro privilegio, se esperaba cobrar más, gracias al elemento coactivo que representaba la fortaleza de El Castellar.

Este objetivo probablemente se cumplió. En 1093 Sancho Ramírez realizó unas donaciones al monasterio benedictino de San Ponce de Tomeras con motivo de la entrada de su hijo Ramiro - futuro Ramiro II, tras la muerte de su hermano Alfonso I sin descendencia - , en la institución a la temprana edad de siete años. Entre estas donaciones aparecen las siguientes: «Similiter dono pariam et tributum ac fabricam que mihi soliti erant facere ipsi hismaelite cum omnibus seruitis que debent facere», sin especificar más. Y más abajo podemos leer que:

Simili modo dono decimam de paria predicti castri [Argedas] et de termino suo [...] Similiter dono ipsam decimam de illa paria de castro quod dicitur Ualterra et Quatreti et de omni termino suo, cum ecclesiis et capellanis suis que ibidem erunt si uoluntas Dei fuerit, cum decimis et primiciiis simulque oblationibus et pertenenciis suis cum omni ecclesiastico suo.

De este documento deducimos que se están obteniendo parias locales, es decir, parias pagadas por fortalezas concretas, no por entidades políticas mayores. Los lugares a los que se refiere el documento son las actuales poblaciones de Arguedas y Valtierra, en Navarra y sabemos que no estaban bajo el control de la corona aragonesa en ese momento, 1093. Del tercer topónimo, «Quatreti,» que no hemos podido identificar, debía estar próximo a Arguedas y Valtierra, que distan entre sí unos $9 \mathrm{~km}$ y están a $20 \mathrm{~km}$ al norte de Tudela. Pero son localidades situadas al norte del Ebro, mientras que Tudela está al sur.

Valtierra estuvo gobernada por la taifa de Zaragoza en 1093. Lo sabemos porque fue el escenario de una batalla en enero de 1104 en la que Pedro I derrotó al ejército hudí matando a su rey taifa, Al-Mustain y porque además el documento que estamos analizando utiliza la fórmula «si uoluntas Dei fuerit». 
Las parias se estaban cobrando, pero no había aún iglesias ni capellanías establecidas en el territorio, cosa evidente si permanecía bajo dominio musulmán. Sólo si era la voluntad de Dios se conquistaría ese territorio y los ingresos producidos por diezmos y primicias podrían empezar a llegar a las arcas del monasterio de San Ponce.

Otra población cercana bajo dominio musulmán en el momento de ser citada es Tauste. Según un documento de 1094, un décimo de las parias que se obtenían de Tauste fue donado al monasterio de San Juan de la Peña: «Hoc est donatiuum, unam uineam de Sancto Atriano et una terra in Arrotellares et decimam de paria de Tobustum» (Salarrurana, 1909: doc. LI). Tauste no fue conquistada por Aragón hasta 1105, lo cual excluye la posibilidad de que se trate de una almotexena, que sólo se cobraba en zonas fronterizas sin dominador claro.

También contamos con dos menciones cronísticas a este fenómeno que comentaremos a continuación. Al contrario que ocurre con la documentación, la cronística, para el caso de Aragón, aporta muy pocos datos. En los Anales de Cataluña leemos que en 1063 comenzaron los pagos de parias de Huesca a Aragón. (Feliù, 1999: 307)

La Crónica de San Juan de la Peña afirma que el rey de Huesca pagó parias en 1090 (Orcástegui: 1983: 37) a Sancho Ramírez. Esta noticia aparece también en los Anales de Navarra de Moret, que la sitúa un año antes, en 1089 (Moret, 1967: 159). En 1092 volvió a exigir parias a los oscenses, pero éstos decidieron buscar un acuerdo secreto con Alfonso VI, prometiéndole el doble de lo que le pagaban a Aragón (Orcástegui: 1983: 38), que no sabemos a cuánto ascendía.

Castilla, como veremos posteriormente, a veces apoyó al reino de Zaragoza contra Aragón, por ejemplo en el caso de Graus y es posible que mandara apoyos a Huesca a cambio de una buena cantidad de dinero. Aunque también es posible que todo el episodio no sea cierto, pues el autor de esta crónica no tenía mucha simpatía por los castellanos y pone énfasis en la traición de éstos, después de que el rey aragonés le apoyara en Toledo.

\section{Las parias recibidas por Navarra (1035-1076)}

El reino de Navarra tras la muerte de Sancho III el Mayor en 1035 quedaba en una situación muy comprometida. Su territorio estaba encajonado entre los recién creados reinos de Castilla y Aragón. Además, tenía pocas opciones de 
expandirse hacia el sur a costa de los musulmanes, aunque sí que realizaron algunas campañas militares. En 1076 el rey navarro Sancho Garcés IV fue empujado por un barranco y murió. Las sospechas sobre la autoría recayeron sobre su hermano e hipotético sucesor, Ramón. Los nobles navarros se negaron a reconocer como rey al presunto asesino de Sancho Garcés IV, con lo cual Navarra quedó sin rey.

Esto fue aprovechado por Castilla y Aragón, que se repartieron el reino. Castilla conquistó la zona de La Rioja y Aragón se anexionó el resto del reino. Sancho Ramírez llegó hasta Pamplona y fue proclamado rey de Navarra. A partir de 1076 y hasta la muerte de Alfonso I en 1134 Aragón y Navarra formarán una única entidad política, con lo que abordaremos únicamente las parias recibidas por Navarra entre 1035 y 1076.

Según Moret, que cita a otro autor, Luis del Mármol, Navarra impondrá parias a los gobernantes de Huesca y Zaragoza en 1046 tras una campaña victoriosa contra Calahorra y Tudela (Moret, 1967: 725). De 1052 data un documento que es la referencia más antigua que hemos encontrado hasta el momento en la documentación navarroaragonesa relativa a las parias, entendidas como tributos pagados por los musulmanes.

Se trata de la referencia contenida en la fundación del monasterio de Santa María de Nájera, al que el rey García Sánchez III dota con una serie de propiedades, pero además le concede a este monasterio «Parie uero uel tributa mee terre uel illius quod Deus mihi uel meis succesoribus deinceps usque in eternum de terra sarracenorum dederit, do et confirmo decimam partem Sancte Marie» (Rodríguez de Lama, 1976: 45). No queda especificado de dónde provenían las parias, que probablemente vendrían de Zaragoza o quizás de alguna población fronteriza como Tudela.

El siguiente documento que hace referencia a parias es el importante tratado de 1073 entre Al-Muqtadir y Sancho Garcés IV de Navarra, publicado por Lacarra (1981b: 91-92; Falcón, 1998: 44). Es un pacto de alianza, similar al que hemos analizado anteriormente de 1069 entre Sancho Ramírez y Zaragoza, cuyo fin principal fue proteger a la taifa hudí de los ataques del rey aragonés, aunque no el único, pues se alude a que Al-Muqtadir podría hacer uso de los soldados navarros «in aliquas partes» en caso de necesidad.

El rey navarro se ponía a disposición de Al-Muqtadir para defenderle y le otorgaba la posibilidad de convocar nobles navarros para defender Zaragoza si necesitaba auxilio armado. A cambio de todo ello, Al-Muqtadir se comprome- 
tía a pagar doce mil dinares al año (Lacarra, 1981b: 94-95) —es decir, exactamente lo mismo que tributaba a Sancho Ramírez en 1069-sin especificar el modo en que se habría de realizar la entrega. Además, abría la posibilidad de entregar plata como pago, especificando que por cada dinar debería entregarse, en tal caso, 7 dirhams de plata, es decir, un total de 84.000 dirhams de plata.

También, como en el pacto de 1069, se hace referencia a «in ipsos ligamentos primus scriptum est in tali modo», es decir, a acuerdos anteriores que no se han conservado. Este nuevo acuerdo debió tener vigencia como máximo hasta 1076, fecha en la que Sancho Ramírez llegó al trono navarro. Ya bajo gobierno aragonés, contamos con algunas referencias documentales que atestiguan que el obispado de Pamplona recibía algunas cantidades de dinero procedentes de las parias.

Ya en el documento de 1091 de dotación de la iglesia de El Castellar queda claro que con anterioridad a esa fecha Pamplona está recibiendo dinero. En otros dos documentos, uno datado en 1097 y otro entre 1105 y 1115 , donde se confirman los beneficios del obispado de Pamplona encontramos más referencias a parias. En el de 1097 el obispo Pedro solicitaba del Papa Urbano II la protección apostólica y que confirmase sus límites y privilegios. Entre sus privilegios figuran las «pariam Cesarauguste civitatis siue de ceteris sarracenorum terris tuo episcopatui adiacentibus quas a regibus et principibus impetrasti uel impertraueris» (Goñi Gaztambide, 1997: doc. 68), es decir, las parias de Zaragoza y otras ciudades bajo el gobierno musulmán, que no quedan especificadas.

El documento fechado entre 1105 y 1115 es una reclamación del abad de Leire, Raimundo, y sus monjes contra este mismo Pedro, obispo de Pamplona. Ambos religiosos estaban litigando por una serie de beneficios eclesiásticos entre los que aparecen «quadringentos solidos de paria Caesarauguste» (Goñi Gaztambide, 1997: Doc. 107).

Este testimonio no tiene valor para fechar entregas de parias, porque es posterior a cualquier pago de parias a Aragón; de hecho el reino hudí de Zaragoza cae en 1110 en manos de los almorávides. Pero permite confirmar la cantidad que pagaba Zaragoza, ya fuera a Aragón o a Navarra: 12.000 dinares anuales. Es la cantidad que aparece en los pactos de 1069 y 1073, y que queda confirmada por la evidencia archivística.

Recordemos lo que decía el documento de 1063 en el que se dotaba la diócesis de Jaca. Se concedía a esta diócesis «ex ipsis tributis que recipimus in 
presenti uel recipere debemus aut in futuro Deo miserante recipiemus de Caesaraugusta necnon et Tutela de omnibus terciam partem ipsius decimationis supradicte ecclesie et episcopo concedimus et donamus», es decir, la décima parte de la tercera parte. La décima parte de 12.000 dinares son 1.200 dinares y la tercera parte de 1.200 dinares son 400 dinares. Precisamente, estos son los 400 dinares anuales que reclamaba el abad Raimundo de Leire como beneficio eclesiástico, pese a que ya hacía algún tiempo que no se cobraban.

\section{Conclusiones}

La almotexena es una institución propia del reino de Aragón, que no se encuentra en otros lugares. La alta densidad de población de la frontera aragonesa, en contraste con el despoblamiento de la frontera castellana, hace que existan pequeñas aldeas susceptibles de ser sometidas a tributo por parte del poder central aragonés, de ahí que el vocablo sólo aparezca en documentación aragonesa. Sin embargo, no podemos asimilar los pagos de almotexena a los pagos de parias, pues constituyen una realidad distinta.

Las parias eran pagadas por los poderes centrales, reinos como la taifa de Zaragoza y la taifa de Lleida, mientras que las almotexenas eran abonadas por pequeñas aldeas y era un tributo de capitación que debían pagar los musulmanes sometidos (mudaggan) que habitaban en esas poblaciones, de acuerdo a su origen etimológico. Es prácticamente igual a la yizya pagada por los cristianos que vivían bajo el poder islámico, que es el origen de la almotexena. Las parias debían entregarse en oro o metal acuñado, mientras que las almotexenas fueron pagadas normalmente en especie. Asimismo, la almotexena sólo se cobraba en Aragón, mientras las parias son abonadas también a otros Estados cristianos peninsulares.

Además, las parias, como se demuestra en los pactos de protección firmados por Al-Muqtadir implicaban una ayuda militar en el caso de que otros poderes cristianos como Castilla atacasen Zaragoza. La almotexena, al ser un impuesto, no implicaba una obligación de defensa del territorio. No obstante, existen similitudes entre ambos tipos de pagos: ambos derivan de la explotación del territorio musulmán y constituían una fuente extra de ingresos muy importante.

En definitiva, la almotexena refleja que amplias partes de la zona norte de la taifa de Zaragoza habían escapado al control hudí de tal manera que los ara- 
goneses podían imponerles pagos de impuestos, aunque aún se considerasen territorio hudí como se deduce de las referencias documentales a Hispania o villis hispaniae. Los hudíes no podían imponer su dominio en el territorio fronterizo, de ahí que a medida que el reino de Aragón fue avanzando hacia el sur las localidades que tenían que abonar almotexena aumentasen. Además, estas acciones empobrecían la zona, empeorando la situación del reino zaragozano.

Por tanto, las parias fueron una fuente de beneficios muy importante para Aragón durante su período formativo y también, aunque en menor medida, para Navarra. El dinero recibido a través de las almotexenas y las parias sirvió para afianzar el poder de la Corona, que era la receptora del dinero y, en segunda instancia, se encargaba de redistribuirlo en el circuito económico aragonés, principalmente a través de las donaciones a instituciones eclesiásticas que eran los motores económicos del reino. También se gastó dinero en la construcción de grandes obras públicas como fortalezas o edificios religiosos.

Una gran parte de la documentación que hace referencia a parias y almotexenas tiene que ver con donaciones de esos beneficios a instituciones eclesiásticas. Los reyes consideraron que ese dinero era recibido gracias a la voluntad divina y les pareció de justicia destinar una parte sustancial a instituciones eclesiásticas. La dotación de la diócesis de Jaca o las donaciones a monasterios como San Juan de la Peña o Santa María de Nájera son ejemplos de esta redistribución. Y los monasterios y diócesis favorecidos por la Corona consiguieron de este modo distanciarse de otros posibles competidores que les pudieran hacer sombra.

Este dinero donado a la Iglesia posibilitó la financiación de varias construcciones de importancia como la catedral de Jaca - cuya edificación inicial en estilo románico se inició en 1077-, o como el actual monasterio de San Juan de la Peña, comenzado en 1071.

Las parias y las almotexenas se utilizaron, así mismo, para aumentar el potencial militar y la presión sobre los reinos de taifa, como sucedió también en Cataluña. La construcción y dotación de la fortaleza denominada Supercaesaraugusta (El Castellar), muy cercana a Zaragoza, es un expresivo ejemplo de cómo estos ingresos ayudaron al avance hacia el sur. Gracias a estas exacciones, Aragón pudo permitirse construir y mantener ocupada una fortaleza muy cercana al corazón del reino hudí. Y también sirvieron para favorecer a personas fieles al rey y a sus familiares, como se aprecia en el caso de Sancha, quien recibió de su padre Ramiro I las almotexenas de tres aldeas. 
Con respecto a la cronología de las almotexenas en el reino de Aragón, los testimonios más antiguos datan de 1049. Esta institución es citada siete veces en la documentación aragonesa hasta 1101, datándose el resto de alusiones en 1076, 1083, 1093-1095, 1095, 1100 y 1101. Pese al lapso de tiempo transcurrido entre la primera referencia (1049) y la segunda (1076) que hemos localizado, pensamos que la almotexena fue un impuesto que no se dejó de cobrar en ningún momento durante la segunda mitad del siglo XI, si bien el espacio en que se cobró se fue desplazando progresivamente hacia el sur a medida que el reino de Aragón ampliaba sus límites territoriales.

La cronología de las parias es más compleja de fijar, pues Aragón sólo captó parias de la taifa hudí de Zaragoza. Como Zaragoza pagó parias a Castilla, Navarra, Barcelona y el propio reino aragonés, el problema radica en determinar cuándo pagó a cada uno de estos poderes políticos. Dada la naturaleza de las parias que, en definitiva, constituyeron un pago a cambio de protección militar, pensamos que bien pudieron pagarse a un poder cristiano cada vez, a pesar de que la pugna de los reinos cristianos entre sí por obtener estos pagos, fue feroz.

En Navarra contamos con la referencia más antigua, que data de 1046. Es una referencia cronística y, por lo tanto, menos fiable que la recogida en la documentación, pero parece plausible que Huesca y Zaragoza pudieran haber sido sometidas a parias tras esta campaña militar. La siguiente referencia, de 1052, es documental y se encuentra en la donación de García III al monasterio de Santa María la Real de Nájera. Desde 1055 a 1073 se establece una cesura de tiempo en la que pensamos que Navarra no obtuvo parias de Zaragoza.

La primera referencia documental al cobro de parias en Aragón es anterior a 1063 pero de fecha indeterminada. La siguiente es la dotación de la diócesis de Jaca en 1063 y la que nos aparece a continuación es el famoso pacto entre Al-Muqtadir y Sancho Ramírez de 1069, pero que hace referencia a acuerdos anteriores. Por lo tanto, sería plausible sostener que entre 1060 y 1070 Aragón estuvo captando las parias de Zaragoza. La referencia cronística de los Anales de Cataluña atestigua, en este mismo sentido, que en 1063 Aragón estuvo cobrando parias.

Pero a partir de 1073 las parias cambiaron de manos y viajaron hacia Navarra, como recoge el pacto entre Al-Muqtadir y Sancho Garcés IV. Este acuerdo alude, así mismo, a acuerdos anteriores firmados por ambos monarcas, por lo que podemos retrasar hasta 1070 la fecha de inicio de esta segunda 
oleada de parias hacia Navarra. En 1076 Navarra quedó dividida entre Castilla y Aragón, haciéndose Sancho Ramírez con el título de rey de Navarra, por lo este territorio desaparece de la escena política como territorio independiente.

Entre 1069 y 1091 no se han localizado referencias a pagos de parias a Aragón, lo cual nos hace llegar a la conclusión de que no existieron. A partir de 1091 en Aragón entraron de nuevo pagos de parias hasta, al menos, la batalla de Valtierra de 1104 y, probablemente, hasta el final de la existencia del reino hudí. No obstante, la última referencia documental al pago de parias data de 1094 y por ello no estamos en condiciones de precisar más sobre el tiempo que la taifa zaragozana estuvo pagando parias a Aragón. No obstante, hay evidencias a tener en cuenta: existe prueba documental de que efectivos militares castellanos encabezados por García Ordóñez apoyaron a Al-Mustain contra Aragón en la batalla de 1096 en Valtierra (Reilly,1988: 283), lo que demuestra que los castellanos habrían pasado a cobrar las parias hudíes y por ello auxiliaron a los zaragozanos contra Pedro I.

La cantidad percibida anualmente probablemente sería el equivalente a 12.000 dinares, ya fuera todo en oro o parte en oro y parte en plata, como se deduce de los pactos firmados por Al-Muqtadir y el pleito entre Leire y Pamplona. En 1110 los almorávides tomaron Zaragoza y acaban las posibilidades cristianas de seguir captando dinero de los hudíes.

El análisis de los pagos de parias es un instrumento esencial para entender la Península Ibérica del siglo XI. Un instrumento del cual se valieron los cristianos para aprovechar la debilidad musulmana en ese nuevo balance de fuerza que se estableció en la Península Ibérica tras la caída del Califato.

\section{Referencias bibliográficas}

ABD Allah [1981] El siglo XI en primera persona. Las memorias de Abd Allah, último rey zirí de Granada, destronado por los almorávides (1090). Madrid, Alianza.

Baigés Jardí, Ignasi J., Gaspar Feliù, Josep M. SAlrach, dirs., (2010) Els pergamins del arxiu comtal de Barcelona: de Ramón Berenguer II a Ramón Berenguer IV. Volum I. Barcelona, Fundación Noguera.

BALAÑá I ABADÍA, Pere (1993) Els musulmans à Catalunya (713-1153): assaig de síntesi orientativa. Sabadell, Ausa.

Balarí Jovany, José (1964) Orígenes históricos de Cataluña. San Cugat del Vallès, Instituto internacional de cultura románica - Abadía de Sant Cugat del Vallés. (Primera edición, Barcelona: Hijos de J. Jepús, 1899). 
Bishko, Charles Julian (1980) «Fernando I and the origins of the Leonese-Castilian alliance with Cluny.» En Studies in Medieval Spanish Frontier History, London, Variorum Reprints: 1-136.

Bonnassie, Pierre (1975) La Catalogne du milieu du x a la fin du XI Siècle, Croissance et mutations d'une sociètè. Tome II. Toulouse, Université de Tolouse-Le Mirail.

CANELlas LóPEZ, Ángel (1993) La colección diplomática de Sancho Ramírez, Zaragoza, Real Sociedad Económica Aragonesa de Amigos del País.

CoRRIENTE, Federico (2003) Diccionario de arabismos y voces afines en iberorromance, Madrid, Gredos.

GARCíA FITZ, Francisco (2002) Relaciones políticas y guerra. La experiencia castellano-leonesa frente al Islam. Siglos XI-XIII. Sevilla, Universidad.

GonzÁlez Miranda, Marina (1955) «La condesa doña Sancha y el monasterio de Santa Cruz de la Serós», Estudios de Edad Media de la Corona de Aragón, 6: 185-202.

GoÑ Gaztambide, José (1997) Colección diplomática de la Catedral de Pamplona (829-1243), Pamplona, Gobierno de Navarra.

Grassotti, Hilda (1964) «Para la historia del botín y de las parias en Castilla-León» Cuadernos de historia de España, 39-40: 43-132.

FALCón PÉREZ, M. a Isabel (1998) La sociedad aragonesa medieval. Zaragoza, Librería General.

Feliú de la Peña y Farell, Narciso [1999] Anales de Cataluña. Edición facsimilar de la de 1709, con estudio introductorio de Jaume Sobrequés y Callicó. Barcelona, Generalitat de Catalunya.

Kosto, Adam J. (2001) Making agreements in medieval Catalonia: power, order and the written world, 1000-1200, Cambridge, Cambridge University Press.

Lacarra de Miguel, José M. (1952) «El rey Lobo de Murcia y el señorío de Albarracín.» En Estudios dedicados a D. Ramón Menéndez Pidal. Tomo III. Madrid, CSIC: 515-526.

Lacarra de Miguel, José M.a (1981a). «Aspectos económicos de la sumisión de los reinos de taifas (1010-1102).» En Colonización, parias, repoblación y otros estudios, Zaragoza, Anúbar: 43-76.

LaCARra de Miguel, José M. a (1981b) «Dos tratados de paz y alianza entre Sancho el de Peñalén y Moctadir de Zaragoza (1069 y 1073).» En Colonización, parias, repoblación y otros estudios. Zaragoza, Anúbar: 79-94.

Laliena Corbera, Carlos (1996) La formación del Estado feudal: Aragón y Navarra en la época de Pedro I. Huesca, Instituto de Estudios Altoaragoneses.

Laliena Corbera, Carlos (2009) «Guerra santa y conquista feudal en el noreste de la península Ibérica a mediados del siglo xI: Barbastro, 1064.» En Cristianos y musulmanes en la Península Ibérica: la guerra, la frontera y la convivencia. XI Congreso de estudios medievales, León, 23-26 de octubre de 2007. Ávila, Fundación Sánchez Albornoz, 187-218.

Lapeña Paúl, Ana Isabel (2004). Sancho Ramírez, rey de Aragón (¿1064?-1094) y rey de Navarra (1076-1094). Gijón, Trea. 
LAPESA, Rafael y Constantino GARCía, eds., (2003). Léxico hispánico primitivo (siglos VIII al XII). Versión primera del Glosario del primitivo léxico iberorrománico. Madrid, Real Academia Española de la Lengua-Fundación Ramón Menéndez Pidal, Espasa-Calpe.

Ledesma Rubio, M. . ${ }^{a}$ Luisa (1996) «Los mudéjares y la fiscalidad.» En M. ${ }^{a}$ Luisa Ledesma, Estudios sobre los mudéjares en Aragón. Teruel, Centro de Estudios Mudéjares: 21-35.

Miranda García, Fermín (2008), «Algunas propuestas sobre transformaciones sociales y renacimiento urbano en el reyno de Pamplona (ca. 1050-1080).» En José Ángel García de Cortázar, coord., García Sánchez III «el de Nájera» un rey y un reino en la Europa del siglo XI: (XV Semana de Estudios Medievales, Nájera, Tricio y San Millán de la Cogolla del 2 al 6 de agosto de 2004). Logroño, Instituto de Estudios Riojanos: 173-190.

Moret, José de [1969] Annales del Reyno de Navarra. Edición facsimilar de la de 1766. Bilbao, Biblioteca de la Gran Enciclopedia Vasca.

Negro Cortés, Adrián E. (2013) «Las parias abonadas por el Reino de Granada: aproximación a su estudio (1246-1464)», Roda da Fortuna, 2, 1-1: 382-396.

Negro Cortés, Adrián E. (2017) «Las parias en la historia medieval española», Catálogo de investigación joven en Extremadura, Cáceres, Universidad de Extremadura: $255-258$.

OrCÁstegui Gros, Carmen (1978) La crónica de los reyes de Navarra del príncipe de Viana: Estudio, fuentes y edición crítica, Pamplona, Diputación foral de Navarra e Institución Príncipe de Viana.

Orcástegui Gros, Carmen (1983) Crónica de San Juan de la Peña (versión aragonesa) Edición crítica, Zaragoza, Institución Fernando el Católico.

Pastor SÁnchez, M. ${ }^{a}$ Victoria (2005) Informe de la prospección arqueológica y delimitación de yacimientos del Término Municipal de Monflorite-Lascasas (Huesca) para la elaboración del Catálogo de yacimientos arqueológicos y su inclusión en el Plan General de Ordenación Urbana de Monflorite-Lascasas (Huesca). Disponible en: http://www.monflorite-lascasas.es/pub/documentos/documentos_ Catalogo_5_770d4170.pdf

Pérez GonzÁlez, Maurilio (1997) Crónica del Emperador Alfonso VII, León, Universidad.

ReILly, Bernard F. (1988) The kingdom of Leon-Castilla under Alfonso VI (10651109), Princeton, Princenton University Press.

Rodríguez de LAMA, Idelfonso (1976). Colección diplomática medieval de La Rioja. Tomo II: Documentos 923-1168, Logroño, Instituto de Estudios Riojanos.

RODRÍGUEZ LATORRE, Luis Eduardo (1995) «Ingresos monetarios en concepto de parias en el Reino de Navarra. Repercusiones políticas, económicas, sociales y culturales.» En José Ignacio de la Iglesia Duarte, $V$ Semana de Estudios medievales, Nájera, 1-5 agosto 1994, Logroño, Instituto de Estudios Riojanos: 241-253. 